\title{
Tackling the tumor microenvironment: what challenge does it pose to anticancer therapies?
}

\author{
Fei Chen ${ }^{1}$, Xinyi Qi ${ }^{2}$, Min Qian ${ }^{1}$, Yue Dai ${ }^{1}$, Yu Sun ${ }^{1,2,3,4 \bowtie}$ \\ ${ }^{1}$ Institute of Health Sciences, Shanghai Institutes for Biological Sciences, Chinese Academy of Sciences, Shanghai 200031, \\ China \\ 2 School of Medicine, Shanghai Jiao Tong University, Shanghai 200025, China \\ ${ }^{3}$ VA Seattle Medical Center, Seattle, WA 98108, USA \\ ${ }^{4}$ Department of Medicine, University of Washington, Seattle, WA 98195, USA \\ $\triangle$ Correspondence: sunyu@sibs.ac.cn (Y. Sun) \\ Received July 8, 2014 Accepted July 28, 2014
}

\begin{abstract}
Cancer is a highly aggressive and devastating disease, and impediments to a cure arise not just from cancer itself. Targeted therapies are difficult to achieve since the majority of cancers are more intricate than ever imagined. Mainstream methodologies including chemotherapy and radiotherapy as routine clinical regimens frequently fail, eventually leading to pathologies that are refractory and incurable. One major cause is the gradual to rapid repopulation of surviving cancer cells during intervals of multiple-dose administration. Novel stressresponsive molecular pathways are increasingly unmasked and show promise as emerging targets for advanced strategies that aim at both de novo and acquired resistance. We highlight recent data reporting that treatments particularly those genotoxic can induce highly conserved damage responses in non-cancerous constituents of the tumor microenvironment (TMEN). Master regulators, including but not limited to NF-kB and C/EBP- $\beta$, are implicated and their signal cascades culminate in a robust, chronic and genome-wide secretory program, forming an activated TMEN that releases a myriad of soluble factors. The damage-elicited but essentially off target and cell non-autonomous secretory phenotype of host stroma causes adverse consequences, among which is acquired resistance of cancer cells. Harnessing signals arising from the TMEN, a pathophysiological niche frequently damaged by medical interventions, has the potential to promote overall efficacy and improve clinical outcomes provided that
\end{abstract}

appropriate actions are ingeniously integrated into contemporary therapies. Thereby, anticancer regimens should be well tuned to establish an innovative clinical avenue, and such advancement will allow future oncological treatments to be more specific, accurate, thorough and personalized.

KEYWORDS tumor microenvironment, DNA damage, secretory phenotype, therapy resistance, genotoxicity, clinical intervention

\section{INTRODUCTION}

There are obstacles in clinical cancer therapies. For years, solid tumors account for the major burden to human health, and epithelial cancers arising in tissues including lung, breast, prostate, colon, ovary and pancreas constitute approximately $80 \%$ of all cancers (Visvader and Lindeman, 2008). Solid tumor formation involves the co-evolution of neoplastic cells together with extracellular matrix and stroma that covers tumor vasculature and immune cells (Junttila and de Sauvage, 2013). Significant progress has been made in clinical treatments, particularly DNA damage-oriented chemotherapy and radiotherapy. However, vast majority of these therapeutic regimens ultimately fail to cure patients, and even tumors that show dramatic initial responses to therapy frequently relapse as resistant malignancies.

Although the standard care for cancer patients is usually a combination of surgery and DNA damaging therapy for cytoreduction or cytostasis under pathological circumstances, 


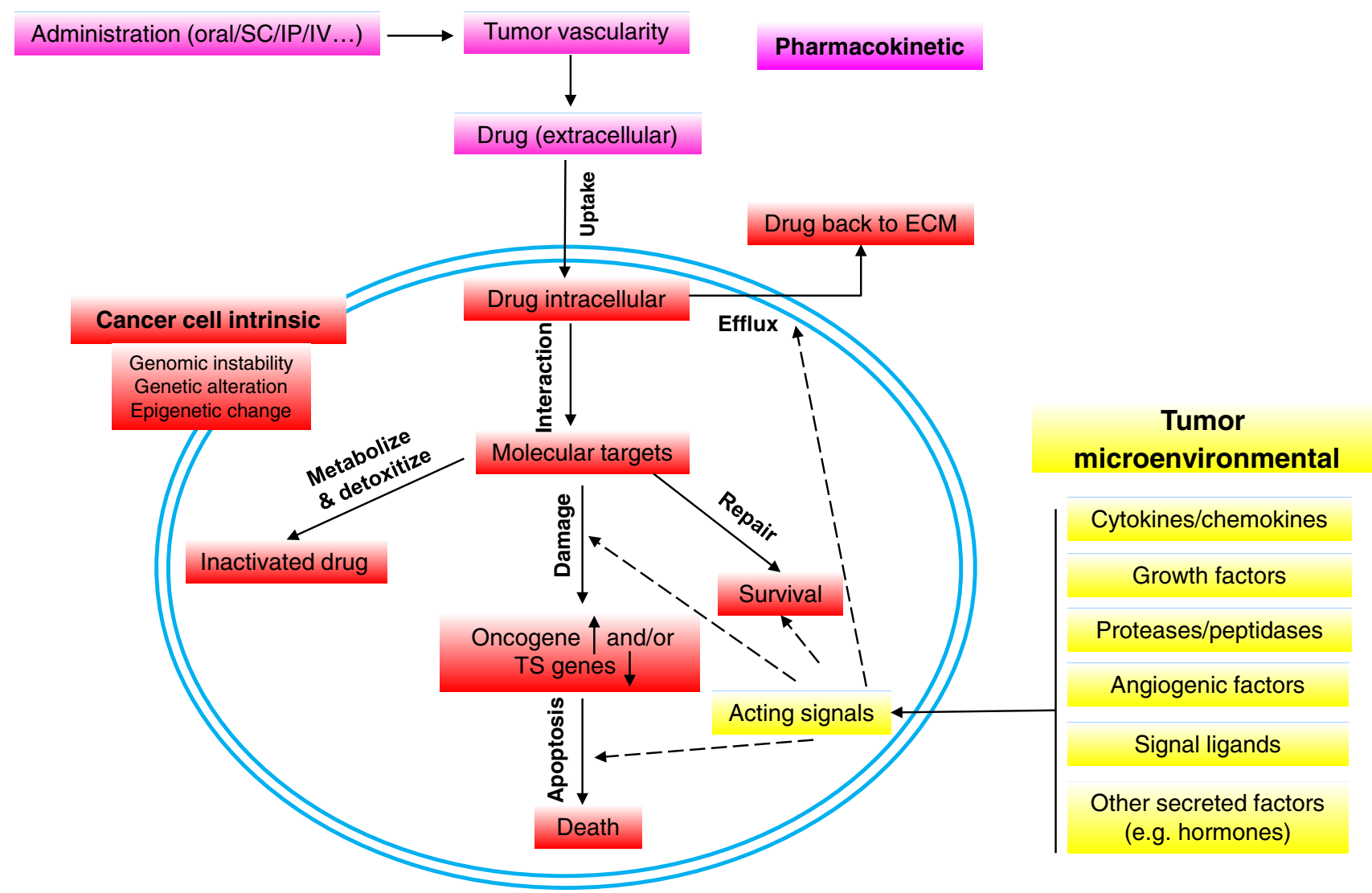

Figure 1. Schematic paradigm of resistance mechanisms in cancer treatment. Mechanisms underlying cancer therapy failure and treatment resistance are summarized. Factors implicated in either pharmacokinetic, cancer cell specific, or tumor microenvironmental categories have functional roles in treatment-induced responses. Changes in intracellular active drug concentrations, drug-target interactions, target-mediated cell damage, damage-induced cell death machineries or the signals from extracellular environments are actively at play under in vivo conditions. In contrast to other factors, the tumor microenvironment contains diverse stromal cell types (fibroblasts, smooth muscle cells, immune cells, endothelial cells, neuroendocrine cells, adipocytes, and pericytes) and comprises a large body of cytokines, chemokines, growth factors, proteinases, and hormones, most of which are signaling ligands, can impact pathophysiological responses to anticancer agents. Thus, the central determinants of therapeutic outcome may be highly dependent upon paracrine survival or stress signals. It is well documented that gene function and relevance varies remarkably when compared in vivo and in vitro, and studying the effect of defined genetic alterations on therapeutic response in either native or damaged tumor microenvironment is critical for effective drug development, personalized anticancer regimes, and optimal design of combination therapies. Colored text boxes: pink, pathways of drug actions; red, processes occurring in cancer cells during disease progression; yellow, signals generated by the tumor microenvironment. SC, subcutaneous injection; IP, intraperitoneal injection; IV, intravenous injection; ECM, extracellular matrix; TS, tumor suppressor.

drug sensitivity is compromised in almost all patients with metastatic diseases. Reasons for such "apparent drug resistance" can be classified into three categories: pharmacokinetic, cancer cell innate and microenvironmental. A basic model of the functional roles of these interactive mechanisms is illustrated in Fig. 1. At molecular levels, although resistance is usually a consequence of cancer cell intrinsic genetic changes including enhanced genomic instability and mutagenesis, epigenetic alterations, decreased oxidative stress, presence of multiple drug resistance (MDR) transporters and up-regulation of drug efflux pumps (Wang and Chen, 2013; Goruppi and Dotto, 2013), an emerging body of studies pinpoints that resistance to cancer therapies is also conferred by cell extrinsic factors such as cytokines, growth factors, proteases and other soluble ligands generated from the TMEN (Campisi, 2013). These factors play key roles in regulating tumor cell proliferation, survival and malignancy through the activation of diverse signaling pathways, including the Smad, PI3K, Jak/ Stat, NF-KB, MAPK, CXCR2 and IL-1 network (Nguyen et al., 2009; Ohanna et al., 2011; Coppé et al., 2011).

While many studies have addressed the activities of tumorproximal factors in cancer progression, relatively few have clarified the role of TMEN in therapeutic outcome. We hereby review that a unique feature of damaged cells resulting from DNA-targeting therapeutics, namely cell non-autonomous secretion, may contribute major extrinsic force towards acquired resistance of cancer cells. The remarkable secretory 
responses of such damaged cells, mainly stromal cells residing in TMEN, may occur in numerous situations. Thus, genotoxic approaches that cause DNA damage response (DDR), unexpectedly, trigger prosurvival signaling in a neoplastic or pre-neoplastic context by providing a micro-reservoir of various pathophysiological conditions that harbor occult arsenals and subsequently fuels tumor relapse. How to overcome these obstacles to successful anticancer treatments remains an increasingly hot topic and requires intelligent inputs from both basic and translational perspectives.

\section{THERAPY-TRIGGERED DAMAGE, CELLULAR SENESCENCE AND SECRETORY PHENOTYPE}

In clinical oncology the most prevalent non-surgery cancer treatments are radiation and chemotherapy, with a shared rationale to generate DNA damage (Jackson and Bartek, 2009; Tell and Wilson, 2010). The premise is that most cancer cells are DDR-dysfunctional, of higher rate metabolism and faster proliferation than most normal cells, with their $S$ phase particularly vulnerable to DNA insults (Pulukuri et al., 2009). Multiple chemotherapeutic drugs are in pre-clinical and clinical trials with an aim to chemosensitize and radiosensitize cancer cells, but they also cause comprehensive senescence, as an alternative to or possibly overlapping with dominant cellular outcomes such as apoptosis, autophagy or mitotic catastrophe. Drug-inducible senescence acts as a cellular effector program and can be induced in vitro by a range of biochemically unrelated DNA damaging anticancer moieties, such as DNA topoisomerase I inhibitor camptothecin, the topoisomerase II inhibitor doxorubicin, the crosslinking agent cisplatin, or to a lesser extent, the anti-metabolite cytarabin. In contrast, some anti-microtubule agents that do not damage DNA such as docetaxel, vincristine or vinblastine basically cause senescence but fail to produce a secretory phenotype (unpublished). It is conceivable that cancer cells in a senescence-like state might remain as "dormant" tumor cells and therefore represent a dangerous potential for tumor relapse (Collado and Serrano 2010). More recently, the biopsy analysis of prostate cancer (PCa) patients demonstrated that a phase II clinical trial of mitoxantrone-involved neoadjuvant chemotherapy induces a typical senescence phenotype followed by the development of secretory features (Sun et al., 2012). Thus, cellular senescence is an early response upon stress and among the biological consequences of genotoxic damage to cells in vivo. A representative list of chemicals that can generate a DDR thereby triggering cellular senescence either in vitro or in vivo is provided in Table 1 . Although a beneficial cellautonomous role of senescence is to facilitate the clearance of senescent cells by the immune system involving inflammatory cells such as macrophages, phagocytes and natural killer (NK) cells, active products of these cells are biologically deleterious and can drive various degenerative pathologies, the most deadly of which is cancer (Chandler and Peters, 2013; Campisi, 2014; Pallasch et al., 2014).
Characterized with either "senescence-associated secretory phenotype" (SASP) (Coppe et al., 2008) or genome-wide "senescence-messaging secretome" (SMS) (Kuilman and Peeper 2009), damaged cells significantly alter surrounding microenvironments through robust secretion of soluble factors. As a full senescence response is not required to initiate this reaction program and acute stressassociated phenotype (ASAP) can appear prior to cellular senescence (Gilbert and Hemann, 2010), a more appropriate term for the chronic response that exerts long term effects after cell exposure to genotoxicity is a "DNA damage secretory program (DDSP)" (Sun et al., 2012). The DDSP is remarkable and distinct in several respects. First, the program is complex, with several hundred proteins induced to varying levels; Second, the program is robust, a large array of transcripts and their attendant proteins, are induced more than 10-fold; Third, there is both consistency and variability in the program depending on the cell type-e.g. fibroblast or epithelium; Fourth, multiple DDSP proteins are well-known to promote disease evolution particularly tumor progression, including proteases (MMPs), growth factors (AREG, EREG), pro-angiogenic factors (ANGPTL4, VEGF), and pro-inflammatory cytokines (IL-6, IL-8) (Coppe et al., 2008; Kuilman et al., 2008; Sun et al., 2012). The enhanced secretion of intracellularly synthesized factors to extracellular space promotes the proliferation and carcinogenesis of epithelial cells, increases angiogenesis, enhances epithelial to mesenchymal transition (EMT), accelerates the invasiveness of transformed cells, and stimulates the growth of xenografted tumors in vivo (Coppe et al., 2008; Sun et al., 2012). Particularly, DDSP occurs after treatment of cancer patients with DNA damaging chemotherapy and cause expression changes of oncogenic nodes in proximal surviving cells, thereby stimulating malignant phenotypes of the tumor (Coppe et al., 2010; Gilbert and Hemann, 2011; Sun and Nelson, 2012).

DDSP factors comprise several families of soluble and insoluble proteins. Such components can affect adjacent niches by activating various cell surface receptors and corresponding signal transduction pathways, actively causing multiple disorders. The secretion of IL-6, a pleiotropic proinflammatory cytokine increases markedly after DNA damage- and oncogene-induced senescence of mouse and human keratinocytes, melanocytes, monocytes, fibroblasts, and epithelial cells (Kuilman et al., 2008). Another upregulated interleukin by senescent cells is the $\mathrm{IL}-1$ complex, whereby both $\mathrm{IL}-1 \alpha$ and $-1 \beta$ are significantly secreted by senescent endothelial cells, fibroblasts, and chemotherapyinduced senescent epithelial cells (Davalos et al., 2010). Chemokine IL-8 (CXCL-8), along with GROa and GRO $\beta$ (CXCL-1, -2) are overexpressed upon senescence (Coppe et al., 2008). Intriguing production of both IL-6 and IL-8 depends on the expression and secretion of IL-1 $1 \alpha$, indicating an internal regulation of DDSP components (Davalos et al., 2010). As typical pro-inflammatory cytokines, IL-6 and IL-8 help reinforce senescence growth arrest in an autocrine manner (Acosta et al., 2008). Other growth factors and 
Table 1. A partial list of DDR-inducing antineoplastic agents in medical oncology, the damage types and correspondingly activated repair pathways in human cells

\begin{tabular}{|c|c|c|c|c|}
\hline Clinical agents & & $\begin{array}{l}\text { Generated } \\
\text { lesion types }\end{array}$ & $\begin{array}{l}\text { Activated repair } \\
\text { pathways }\end{array}$ & References \\
\hline $\begin{array}{l}\text { Radiotherapy } \\
\text { and } \\
\text { radiomimetics }\end{array}$ & $\begin{array}{l}\text { Bleomycin (Blenoxane) } \\
\text { lonizing radiation }\end{array}$ & $\begin{array}{l}\text { BD, } \\
\text { DSBs, } \\
\text { SSBs }\end{array}$ & $\begin{array}{l}\text { BER, HR, NHEJ, } \\
\text { SSBR }\end{array}$ & $\begin{array}{l}\text { Helleday et al., 2008; Jackson and Bartek, } \\
\text { 2009; Tell and Wilson, 2010; Costantino et } \\
\text { al., 2014; Helleday et al., } 2014\end{array}$ \\
\hline $\begin{array}{l}\text { Monofuncational } \\
\text { alkylators }\end{array}$ & $\begin{array}{l}\text { Alkylsulphonates } \\
\text { Ethylenimes } \\
\text { Nitrosourea compounds } \\
\text { Piperazines } \\
\text { Procarbazine } \\
\text { Temozolomide } \\
\text { Triazenes }\end{array}$ & $\mathrm{BD}, \mathrm{BDAs}, \mathrm{RLs}$ & $\begin{array}{l}\text { BER, DR, ENDO, FA, } \\
\text { HR, NER, RecQ, TLS }\end{array}$ & $\begin{array}{l}\text { Helleday et al., 2008; Jackson and Bartek, } \\
\text { 2009; Tell and Wilson, 2010; Sale et al., } 2012\end{array}$ \\
\hline $\begin{array}{l}\text { Bifunctional } \\
\text { alkylators }\end{array}$ & $\begin{array}{l}\text { Carboplatin/Cisplatin } \\
\text { Cyclosporamide } \\
\text { Mitomycin C } \\
\text { Nitrogen mustard } \\
\text { Psoralen }\end{array}$ & $\begin{array}{l}\text { BDAs, DSBs, } \\
\text { DNA crosslinks, } \\
\text { RLs }\end{array}$ & $\begin{array}{l}\text { ENDO, FA, HR, NER, } \\
\text { RecQ, TLS }\end{array}$ & $\begin{array}{l}\text { Helleday et al., 2008; Jackson and Bartek, } \\
\text { 2009; Sale et al., 2012; Costantino et al., } \\
\text { 2014; Helleday et al., } 2014\end{array}$ \\
\hline Antimetabolites & $\begin{array}{l}\text { 5-Fluorouracil } \\
\text { Folate analogues } \\
\text { Thiopurines } \\
\text { Thioguanine }\end{array}$ & $\begin{array}{l}\text { BD, cytotoxic } \\
\text { metabolites, } \\
\text { RLs }\end{array}$ & BER & $\begin{array}{l}\text { Helleday et al., 2008; Jackson and Bartek, } \\
\text { 2009; Tell and Wilson, 2010; }\end{array}$ \\
\hline $\begin{array}{l}\text { Topoisomerase } \\
\text { inhibitors }\end{array}$ & $\begin{array}{l}\text { Camptothecins (Topo I) } \\
\text { Etoposide (Topo II) } \\
\text { Anthracyclines } \\
\text { Epirubicin } \\
\text { Daunorubicin } \\
\text { Doxorubicin } \\
\text { Mitoxantrone } \\
\text { Idarubicin }\end{array}$ & $\begin{array}{l}\text { DSBs, RLs, } \\
\text { SSBs, some } \\
\text { also produce } \\
\text { free radicals } \\
\text { (e.g. anthracy- } \\
\text { clines) }\end{array}$ & $\begin{array}{l}\text { ENDO, FA, HR, NHEJ, } \\
\text { RecQ, SSBR }\end{array}$ & $\begin{array}{l}\text { Helleday et al., 2008; Jackson and Bartek, } \\
\text { 2009; Costantino et al., 2014; Helleday et al., } \\
2014\end{array}$ \\
\hline $\begin{array}{l}\text { Replication } \\
\text { inhibitors }\end{array}$ & $\begin{array}{l}\text { Actinomycin D } \\
\text { (Dactinomycin, disrupts } \\
\text { RNA and synthesis) } \\
\text { Aphidicolin } \\
\text { Arabinosylcytosine (araC) } \\
\text { Chromomycin } \\
\text { (anthraquinone) } \\
\text { 5-fluorouracil } \\
\text { Gemcitabine } \\
\text { Hydroxyurea } \\
\text { Mercaptopurine } \\
\text { Methotrexate } \\
\text { Plicamycin }\end{array}$ & DSBs, RLs & $\begin{array}{l}\text { ENDO, FA, HR, NHEJ, } \\
\text { RecQ }\end{array}$ & $\begin{array}{l}\text { Helleday et al., 2008; Jackson and Bartek, } \\
\text { 2009; Costantino et al., 2014; Helleday et al., } \\
2014\end{array}$ \\
\hline
\end{tabular}

$\mathrm{BD}$, base damage; BER, base excision repair; DR, direct reversal; DSB, double strand break; ENDO, endonuclease-mediated repair; FA, Fanconi anaemia repair pathway; HR, homologous recombination; NER, nucleotide excision repair; NHEJ, non-homologous end joining; RecQ, RecQmediated repair; RL, reversal lesion; SSB, single strand break; SSBR, single strand break repair; TLS, translesion synthesis.

inflammatory cytokines including AREG, EREG, CXCL-3, CXCL-14, and IL-23A are also synthesized and secreted by DNA-damaged stromal cells (Sun et al., 2012).

Remarkably the matrix metalloproteinases (MMPs) family members are upregulated in senescent fibroblasts in particular stromelysin-1 and -2 (MMP-3, -10) and collagenase-1 (MMP-1) (Liu and Hornsby 2007). MMPs produced by senescent cells can regulate the activity of the soluble factors present in DDSP by cleaving MCP-1, -2 , and -4 and IL- 8 (Kessenbrock et al., 2010). Serine proteases secreted as part of DDSP are regulators of the plasminogen activation pathway: urokinase- or tissue-type plasminogen activators (UPA or IPA), the UPA receptor (UPAR), and inhibitors of these serine proteases (PAI-1 and -2) (Blasi and Carmeliet, 2002). Senescence-induced changes in cellular metabolism may alter TMEN by secreting certain ligand of $\mathrm{Wnt} / \beta$-catenin pathway, namely WNT16B, as one of the critical DDSP factors that emerged recently. Once released from damaged stromal cells, WNT16B can remarkably promote cancer cell proliferation, migration, invasiveness, and more surprisingly, 
resistance to multiple cytotoxic treatments both in vitro and in vivo (Sun et al., 2012).

Interestingly, certain stromal components may have beneficial effects as a bright side such as tumor suppression, immune clearance, tissue repair (Ozdemir et al., 2014; Rhim et al., 2014), and particularly, chemosensitizing, for example, suppression of the secretion phenotype through NF-KB inhibition promoted resistance to chemotherapy in a mouse lymphoma model (Chien et al., 2011). Such a beneficial effect of senescent cells on pathology poses a paradox because wound healing and tissue repair decline with age. How to resolve such paradoxes? The transient presence of senescent cells may be beneficial, whereas their chronic contribution including creating local (and possibly systemic) inflammation, disrupting normal tissue structure and function, and fueling aging related pathologies in multiple recurrent malignancies, becomes undoubtedly deleterious in the late stage of lifetime (Campisi, 2013).

\section{REGULATORY NETWORK OF SENESCENCE AND SECRETION PHENOTYPE}

Mechanistically a DDR is indispensable for the increased secretion of a subset of DDSP factors, which initiates a signal amplification cascade to sense DNA damage, inducing cell cycle arrest and DNA lesion repair (Rodier et al., 2009). If the extent of DNA damage is irreparable, such a DDR becomes persistent so that distinct nuclear structures termed DNA-SCARS (DNA segments with chromatin alterations reinforcing senescence) form and the cell enters senescence but maintains a chronic, low level DDR (d'Adda di Fagagna, 2008; Rodier et al., 2011). Persistent DDR is necessary for a robust DDSP, while the upstream components of the DDR complex particularly ATM/NBS1/CHK2 transcriptionally regulate many DDSP elements through activating NF-KB and/or CCAAT-enhancer-binding proteinbeta $(C / E B P-\beta)$, nuclear factors persistently active in senescent cells (Kuilman et al., 2008; Acosta et al., 2008; Fumagalli and d'Adda di Fagagna, 2009). Deletion of C/EBP- $\beta$ abrogates the enhancement of both IL- 6 and IL-8, the most upregulated cytokines at senescence, and NF-KB knockdown significantly decreases the expression levels of majority (75\%) DDSP factors (Acosta et al., 2008; Kuilman et al., 2008). In many cell types, an early response to senescence-inducing stimuli is increased expression of IL$1 \alpha$, a plasma membrane-associated cytokine that binds its plasma membrane-associated receptor (IL-1R), which in turn initiates a signaling cascade that ultimately activates NF-KB (Orjalo et al., 2009).

As part of the acute secretory responses that occur in certain contexts, cytokines including IL- 6 and Timp- 1 are released in thymus after DNA damage, thereby creating a "chemoresistant milieu" that promotes the survival of a minimal residual tumor burden via protecting lymphoma cells from demise induced by doxorubicin (Gilbert and Hemann, 2010). Importantly, IL-6 production occurs as a result of p38 mitogen-activated protein kinase (p38MAPK) activation in tumor-associated endothelial cells rapidly after genotoxicity, an acute cytokine release that was also observed in treated human endothelial and hepatocellular carcinoma cells. Similarly, p38MAPK/MAPKAPK-2 pathway is activated in $\mathrm{H}_{2} \mathrm{O}_{2}$-treated human stem cells and is responsible for establishing an irreversible cell cycle arrest typical of senescence that is caused by permanent reactive oxygen species (ROS) production, where increased functional mitochondria are involved (Borodkina et al., 2014). Further, p38MAPK governs a posttranscriptional mechanism that sustains the protumorigenic DDSP, while inhibition of p38MAPK abrogates the tumor-promoting activities of cancer associated fibroblast (CAFs) and senescent fibroblasts (Alspach et al., 2014). Thus, p38MAPK is a TMEN-specific Achilles' heel that may be exploited as a new therapeutic target. Although DNA damage signaling implicates the activity of p38MAPK (Köpper et al., 2013), a stress-responsive MAPK pathway component, it was reported that this kinase induces senescence by a DDRindependent mechanism (Freund et al., 2011). To date, even it is established that mitogenic signals ultimately activates the p53/p21 and/or p16INK4a/RB pathways (Campisi, 2013), how p38MAPK is engaged in response to genotoxic stress and how it relays signals to the downstream pathways to induce the expression of a full spectrum of DDSP effectors remains largely unknown, and continued inputs to completely clarify the entire and detailed reaction chain are needed.

Two microRNAs, namely miR-146a and miR-146b (miR$146 \mathrm{a} / \mathrm{b}$ ), negatively regulate the senescence-associated secretion of IL-6 and IL-8 (Bhaumik et al., 2009). These microRNAs are strongly upregulated in senescent human fibroblasts with a DDSP, dampening inflammatory cytokine secretion by reducing NF-KB activity through direct targeting IRAK1, eventually suppressing IL-6/8 secretion (Taganov et al., 2006). To the contrary, inhibition of IL-1R signals from downstream can curtail miR-146a/b level, demonstrating the implication of microRNAs in a negative NF-KB feedback loop of secretory regulation between $\mathrm{IL}-1 \alpha$ and $\mathrm{miR}-146 \mathrm{a} / \mathrm{b}$ (Freund et al., 2010). The studies again highlight the essential role of NF-KB, and indicate miR-146a/b as central players of interleukin secretion within the DDSP network. More recently it was reported that stimuli inducing cell senescence, such as $\mathrm{y}$-irradiation and standard $\mathrm{O}_{2}$ concentration, can increase expression of miR-335, which correlates with senescence/aging in human mesenchymal stem cells (hMSCs) and inhibits their therapeutic actions through inhibition of AP-1 activity. Vice versa, forced expression of miR-335 resulted in early senescence-like alterations in hMSCs, including increased SA- $\beta$-gal activity and cell size, reduced cell proliferation capacity, augmented p16 expression, and more importantly, the development of a DDSP phenotype, indicating that miR-335 plays a key function in the regulation of reparative activities of hMSCs and that it not only mediates senescence/DDSP signaling but might be 
considered a marker for the therapeutic potency of these cells in clinical applications (Tomé et al., 2014).

Thus, as evidenced by multiple studies, DNA damage is able to force surviving cells to enter senescence and engage a fairly complicated network that mediates the development of a signal transduction cascade. Damaged cells thereby exert comprehensive impacts to surrounding tissues with the accompanying, inherent, and conserved phenotype-DDSP, which can be turned on after clinical administration of genotoxic therapies against the extremely lethal human pathology, cancer (Fig. 2).

\section{TRANSLATIONAL RELEVANCE AND VISTAS}

Cancer is a leading cause of global human mortality, and there is still much than less to do. Cells that are not intrinsically resistant to a drug will rewire their circuitry during treatment to become resistant, without any genetic or epigenetic changes at all (Bourzac, 2014). Various approaches including those to delay resistance acquisition through maintenance therapy are practiced, with a basic notion that resistance can be solved by increasing cancer cell exposure to therapy thereby killing them directly. Both pharmacokinetic and non-pharmacokinetic methods proved to be effective, however, neither side has taken into account of the farreaching impact of therapeutically altered but biologically active TMEN, which once induced can significantly confound the disease control. Surviving cancer cells still proliferate during the intervals between treatments and this process of repopulation frequently results in treatment failure. Innovative strategies are eagerly expected to counteract with cancer cell repopulation during therapy, tackle tumor resistance, thus improving the overall treatment outcome.

\section{Cancer biology}

Upon major DNA damage generated in cancer patients, apoptosis is the immediate response to chemotherapy, occurring within hours following therapy. As tumors that undergo apoptosis in response to therapy fail to display a significant residual tumor mass, it is conceivable that damage aftermath, mainly senescence, occurs at much slower kinetics, serving as a "standby" failsafe program, in case the first-line response is corrupted (Schmitt, 2003).

Emergence of prosurvival, progrowth, and proangiogenic factors derived from damaged TMEN is one of the conserved responses to genotoxic therapies, but in an off-target manner. Of note, multiple soluble factors are substantially released following DNA damage to cells in vivo, and paradoxically, such a secretory phenotype is formed more remarkably in proximal stromal cells than in the cancer population, which should be a major target of damage per se (Sun et al., 2012). For instance, drug treated endothelial cells release IL- 6 and Timp-1, which promote the induction of Bcl-xl in adjacent lymphoma cells (Gilbert and Hemann, 2010). In such a case, proapoptotic signaling induced by the first salvos of chemotherapy on cancer cells is counteracted by anti-apoptotic signals emanating from the passively engaged vascular compartment in a damaged TMEN.

While the complete signal network starting from a DNA damage response to increased secretion still remains unclear, it involves the activation of stress responsive cascades-most notably the NF-KB signaling pathway. The NF$\mathrm{KB}$ family of transcription factors plays indispensable roles in regulating expression of many SASP components. Constitutive blockade of NF-KB nuclear translocation through mutations in the IKBa gene, not only inhibited expression of multiple cytokines including the GRO family members, but also drastically attenuated WNT16B synthesis by the damaged prostate fibroblasts (Sun et al., 2012). On the other hand, intact NF-KB signaling is not only an essential pathway in many cancer entities, such as mucosa-associated gastric lymphoma, Hodgkin's disease, and diffuse large-B-cell lymphoma, but can compromise the response to anticancer therapies (Schmitt 2003). Thus, the NF-kB complex seems to be implicated in both the development of a secretory phenotype of damaged stromal cells, and vital activities particularly survival of targeted cancer cells, each side is closely associated with acquired resistance. Similarly, the transcription factor C/EBP- $\beta$ cooperates with IL- 6 to activate the inflammatory network, while C/EBP- $\beta$ depletion abrogates both IL-6 and IL-8 expression (Kuilman et al., 2008). Thus, novel agents with the ability to preferentially target NF$\mathrm{KB}$ and $\mathrm{C} / \mathrm{EBP}-\beta$ in human cells thereby dampening the development of a typical secretory phenotype will likely lead to clinical amelioration.

Poly (ADP-ribose) polymerase 1 (PARP-1) detects DNA lesions and promotes DNA repair, but can also mediate NF$\mathrm{KB}$ activation upon genotoxic stress, as suppression of NF$K B$ activity and CCL2 secretion by the PARP-1 inhibitor 3-AB diminishes a secretome in senescent melanoma cells (Ohanna et al., 2011). Thus, the combination of temozolomide or fotemustine with PARP-1 inhibitors in clinical trials (Helleday et al., 2008) or with NF-kB inhibitors (e.g. sulfasalazine, in clinics for inflammatory bowel diseases) may confer potent anti-tumor efficacy and improve the therapeutic index by hypersensitizing melanoma cells to DNA damage while preventing the deleterious side effects. As a proof, PARP-1 inhibition in melanoma and cervical carcinoma lines enhanced in vitro sensitivity to temozolomide (Tentori et al., 2010) and promotes antitumor activity in ETS gene-rearranged PCa models (de Bono et al., 2011). These data provide strong support for the development of PARP1 or NF$\mathrm{KB}$ blockage strategies in combination with the current anticancer drugs, and open new avenues for more effective therapeutic intervention.

Recently immunotherapeutics have entered clinics, largely on the basis of the recognition that several types of immune activities are correlated with tumor development. Although resistance-augmenting microenvironments represent a major barrier to effective elimination of multiple malignancies, combination regimens including synergistic 


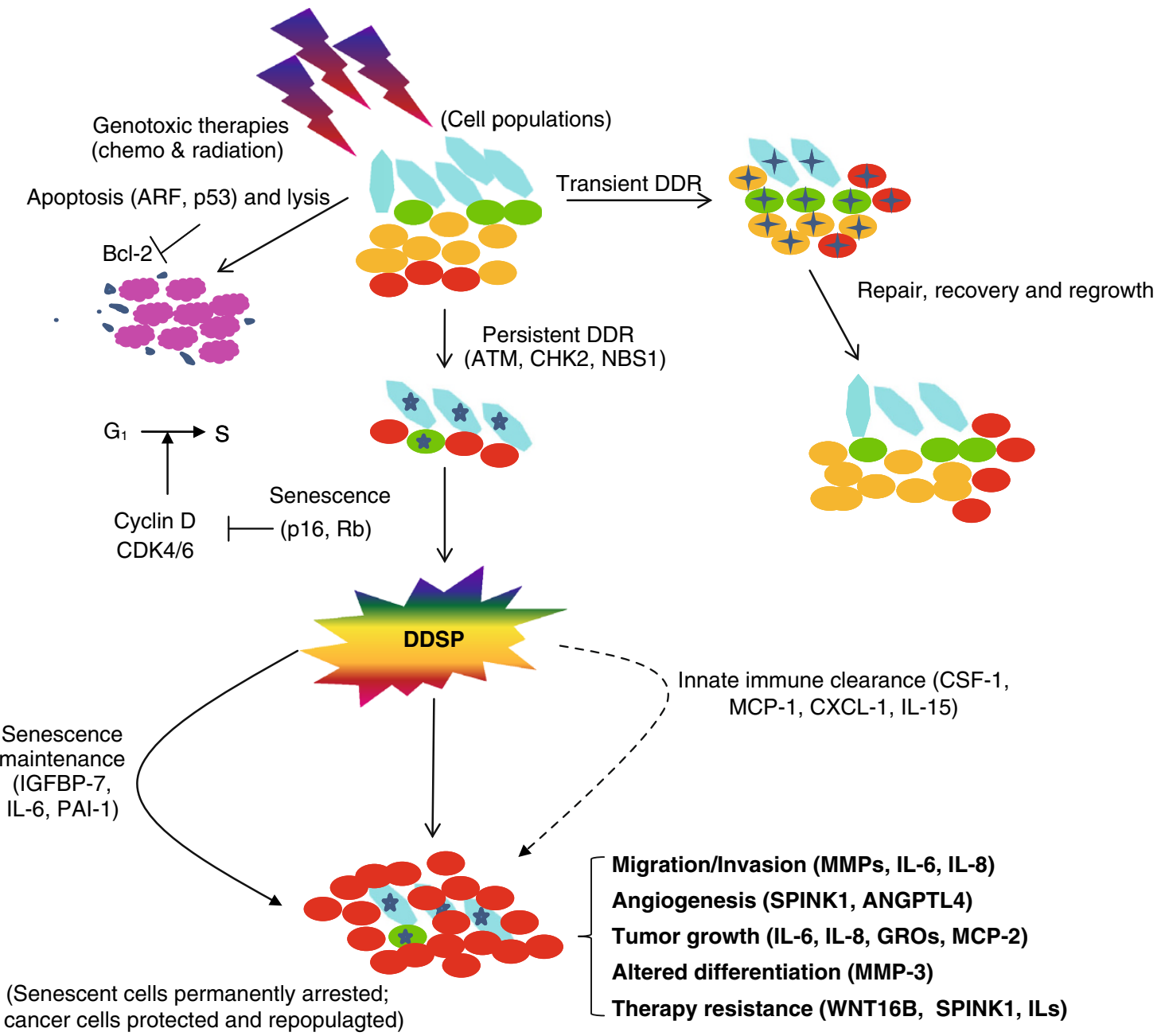

Figure 2. Therapy-induced DDR activation triggers the DDSP program and exerts a profound impact to cancer phenotypes. Upon therapeutic genotoxicity that mainly targets cancer cells, which are in active phases of turnaround and proliferation, cells within the TMEN have several responses. At minor damage, such as low doses of irradiation ( $0.5 \mathrm{~Gy}$ ), DDR foci disappear within hours after complete DNA damage repair. In contrast, at higher doses ( $\geq 5 \mathrm{~Gy}$ ), most damage foci in stromal cells persist for longer period, and cells enter senescence. Concurrently, majority of cancer cells are sensitized to such severe damage and directly go to apoptosis, while those with DDR-deficiency circumvent apoptosis and survive through treatment. High dosage of DNA damage usually triggers a persistent DDR engaging ATM, CHK2, and NBS1 which activates the cell cycle effectors p53/p16/RB, and leads to continuous and robust secretion of a large spectrum of proteins, dictated by a program coined as DDSP. A few secreted factors function in a cellautonomous manner, such as IGFBP-7, IL-6, PAI-1, reinforcing senescence through a positive feedback loop that sustains the DDR. Several inflammatory cytokines (for example, CSF-1, MCP-1, CXCL-1, and IL-15), act in a cell non-autonomous way, and potentiate tumor regression by inducing the innate immune response that promotes tumor clearance. However, most components of the secretory phenotype promote cancer progression by enhancing survival, migration, invasiveness, and angiogenesis, accelerating cell repopulation, altering epithelial differentiation and causing epithelial-mesenchymal transition (EMT, e.g. IL-6, IL-8 and recently reported WNT16B and SPINK1). An advanced cancer phenotype, therapy resistance, hereby forms and once activated by such a program, cancer cells are more malignant and refractory to subsequent cycles of therapies. Colored cells: cyan, fibroblasts; green, smooth muscle cells; orange, benign epithelial cells; red, neoplastic epithelial cells; magenta, apoptotic cells; cross-shaped, cells undergoing transient DDR and in acute repair phase; star-shaped, cells that are permanently damaged, become senescent, and exhibit DDSP hallmarks.

chemoimmunotherapeutic approach that involves anti-CD20 (or anti-CD52) turns out to be a potent strategy for using conventional anticancer agents to alter the TMEN and promote the efficacy of targeted treatments (Coussens et al.,
2013; Palucka and Banchereau 2014; Pallasch et al., 2014). Alternatively, some agonistic monoclonal antibodies, specific to certain molecules including those on the top list of DDSP factors or critical signaling nodes of damage response, have 

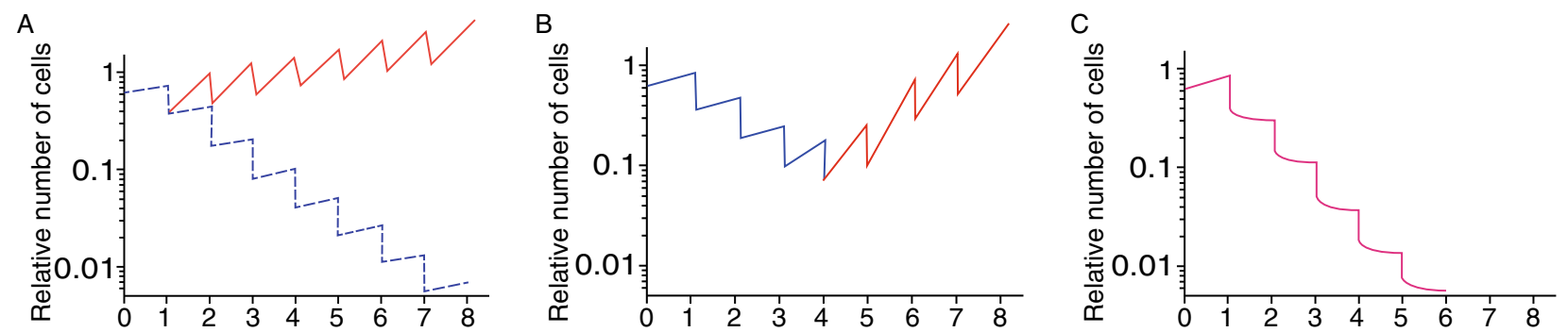

Cycles of chemotherapy at 3-week intervals

Cycles of chemotherapy at 3-week intervals

Cycles of chemotherapy at 3-week intervals

Figure 3. Potential effects of repopulation on total cell number between therapeutic cycles and a proposed clinical solution to circumvent pathological consequences. (A) Although a large portion of cancer cells is killed after each dose of administration, such as those given at 3-week intervals of radiation or chemotherapies, surviving cells can repopulate within a TMEN during the overall treatment period. Here, a constant rate of repopulation between doses is assumed, characterized by a doubling time of either 10 days (solid lines, red) or 2 months (dashed lines, blue). (B) Accelerating repopulation of surviving cancer cells frequently occurs between consecutive cycles, characterized by the indicated doubling times (blue line, cell number reduction phase; red line, increase phase). Such tendency can lead to cancer remission and regrowth, a phenomenon commonly observed in clinical practice, without any change in the cell intrinsic sensitivity to treatments. (C) Novel and innovative regimens integrating therapies that effectively target the DDSP phenotype of damaged TMEN (green arrows) have the advantage to curtail the potential of cancer cell repopulation. Ideally this should be applied consistently between successive courses to achieve optimal outcome in medical oncology.

proved effectiveness through in vitro and in vivo studies (unpublished). Once approved to enter clinical trials, they will demonstrate the values in circumventing the side-effects of DNA-damaging treatments. In a long term, it benefits to develop medication that enhances DNA damage but sever the signaling pathway arising from DDR events to the downstream consequence, DDSP program development, thereby depriving cancer of acquired resistance and reducing disease incidence, progression and mortality.

\section{Clinical management}

Cancer cell repopulation describes the continued proliferation of surviving cancer cells, most of which are usually cancer stem cells (CSCs) and have the capacity to regenerate the tumor, occurs during a course of fractionated radiotherapy or chemotherapy. As a result of influence from the TMEN that not only limits drug distribution but exerts multiple anti-treatment forces, repopulation often has a dominant and limiting effect on therapeutic index, and accelerated repopulation during successive therapy can lead to an initial response followed by tumor regrowth in the absence of intrinsic sensitivity change of cancer cells ( $\mathrm{Yu}$ and Tannock, 2012; Patel et al., 2013; Yu et al., 2013).

Upon chemotherapy tumor growth will follow a Gompertzian curve, and the rate of regrowth would be faster after shrinkage induced by treatment (Norton and Simon, 1986). In a model to mimic the responses of cancer cells during repopulation that occurs in courses of chemotherapy given at three-week intervals, it is reasonable to assume that the rate of repopulation remains constant but increases in the intervals between successive courses of treatment, whereas chemotherapy inhibits proliferation temporarily after treatment but triggers subsequent repopulation which accelerates between successive cycles of chemotherapy (Kim and Tannock, 2005). Increased cellular sensitivity to cytotoxic drugs generated by rapid proliferation might be countered by the tendency to select cells with acquired resistance conferred by enhanced secretion of DDSP factors from adjacent TMEN in the context of hypoxia. In clinical conditions, this problem may be technically solved by artful administration of anti-DDSP agents between cycles of therapy, a feasible and practical way to minimize the influence of cancer-promoting factors from DNAdamaged cells that develop a secretory phenotype (Fig. 3).

Repopulation depends on the activation of specific signaling pathways to promote cancer cell proliferation. In clinical trials, agents including small molecule inhibitors and antibody-based pharmaceuticals can be given concurrently or continually with conventional therapy (Hallek et al., 2014). One caveat is, the results of some trials may not be exciting, as the cytostatic effects of molecule-targeted agents might render tumor cells insensitive to cycle-active chemotherapy. Thus, it is worthwhile to conceive advanced clinical trials, in which adjuvant chemotherapy (cytotoxic) agents are administered but with enhanced specificity to proliferating cells, while novel drugs (cytostatic) targeting DDSP factors are used during therapy courses to shield influence from surrounding stroma. Thus, an ideal approach is to apply these types of treatments sequentially as a metronomic design (Sun and Nelson, 2012). The advantage of such a combinatory treatment is that before the next round of DNAdamaging therapy it will allow cancer cells to re-enter the cycle and regain sensitivity to cycle-active drugs, a regimen leading to improved therapeutic outcome.

On the other hand, despite tremendous resources being exploited in cancer biology and clinical oncology, there are progressively increasing failure rates, high cost, low bioavailability, poor safety, limited efficacy, and a lengthy design 
and testing process associated with cancer drug discovery and development. Exploring established non-cancer drugs for anticancer activity provides an opportunity to rapidly advance therapeutic strategies into clinical trials (Gupta et al., 2013). The impetus for development of cancer therapeutics that specifically manipulate the TMEN to deprive cancer cells of resistance conferred by surrounding niches, stems from the fact that many diseases share common molecular pathways and targets in the cell. For instance, multiple agents that inhibit PAPR1 activity have been approved by FDA and currently applied in non-cancer disease treatments where they demonstrated decent efficacy (Garber, 2013; Harrison, 2013); some antidiabetic chemicals like metformin can suppress the production of inflammatory cytokines generated by senescent cells and inhibit their secretory phenotype by interfering with IKK/NF-KB activation (Moiseeva et al., 2013). Clearly, such drugs have potential to be "repurposed" or "reprofiled" for cancer treatments. The efforts to employ advanced strategies to identify and implement current non-cancer drugs for cancer resistance control should be highly valued and encouraged, and we wish that drug repurposing will play a high-impact role in future anticancer therapies.

\section{CONCLUDING REMARKS AND FUTURE DIRECTIONS}

Considerable progress is made in elucidating the underlying mechanisms of cancer resistance, with expected innovation in therapeutic design, both conceptually and practically. However, much is still in dark and many blanks remain unfilled. By nature, cancer is caused not just by bad cells or bad genes, but also by good ones not doing the right thing - an aspect of the disease that is highly complicated to study and to combat (Bourzac, 2014). The keys to success should include careful evaluation of the preclinical-clinical consequence of tissue damage generated by DNA-targeting therapies. Repopulation during fractionated anti-cancer therapies has long been recognized as an important cause of treatment failure. Recent findings outline a mechanism by which cytotoxic therapies given in cyclical doses can actually augment later treatment resistance and may open the door to new areas of research and to emerging therapeutic targets that implicate the DNA damage response program in certain cell types.

Preclinical trials are ongoing to evaluate strategies to manipulate the distinct phenotype of DNA-damaged cells, and a promising methodology is to combine the use of cytotoxic agents which shrink tumor mass by selectively inhibiting cell proliferation and that of novel drugs to diminish the development of DDSP of damaged TMEN during treatment intervals, a combined and integral approach. Although for new trials prudential scheduling of multiple agents between courses of therapy is not only necessary but essential, priority should be given to experimental and clinical studies of the process, which may be more complicated than thought. Last, but not least, translation of most scientific findings from laboratories to clinics has the potential and holds promise to improve the safety and efficacy of anticancer therapies, by successfully cutting the lifeline of cancer cell populations.

\section{ACKNOWLEDGEMENTS}

We gratefully thank the lab members of Dr. Peter Nelson (Fred Hutchinson Cancer Research Center), Dr. Judith Campisi (Buck Institute for Research on Aging; Lawrence Berkeley National Laboratory), and Dr. Stephen Plymate (University of Washington; VA Puget Sound Health Care System) for inspiring discussion and insightful suggestions. This work was supported by the US Department of Defense (DoD) Prostate Cancer Research Program (PCRP) Idea Development (New Investigator) Award PC111703 (to Y.S.) and the National 1000 Youth Elites Research Program of China (to Y.S.). We sincerely apologize for not being able to make a thorough citation of the literatures contributed by numerous scientists and clinicians working in the relevant fields due to the space limitation.

\section{ABBREVIATIONS}

ASAP, acute stress associated phenotype; CAF, cancer associated fibroblast; C/EBP- $\beta$, CCAAT/enhancer binding protein; CSC, cancer stem cell; DDR, DNA damage response; DDSP, DNA damage secretory program; DNA-SCARS, DNA segments with chromatin alterations reinforcing senescence; hMSC, human mesenchymal stem cell; MDR, multiple drug resistance; MMP, matrix metalloproteinase; NF-kB, nuclear factor kappa-light-chainenhancer of activated $B$ cells; NK, natural killer; PARP-1, poly (ADPribose) polymerase 1; $\mathrm{PCa}$, prostate cancer; p38MAPK, p38 mitogenactivated protein kinase; ROS, reactive oxygen species; SASP, senescence associated secretory phenotype; SMS, senescence messaging secretome; TMEN, tumor microenvironment; tPA, tissue type plasminogen activator; uPA, urokinase plasminogen activator; UPAR, UPA receptor.

\section{COMPLIANCE WITH ETHICS GUIDELINES}

Fei Chen, Xinyi Qi, Min Qian, Yue Dai and Yu Sun declare that they have no conflict of interest.

All institutional and national guidelines for the care and use of laboratory animals were followed. Particularly, animal experiments were conducted in accordance with procedures approved by the IACUC of University of Washington. This article does not contain any studies with human subjects performed by any of the authors.

\section{OPEN ACCESS}

This article is distributed under the terms of the Creative Commons Attribution License which permits any use, distribution, and reproduction in any medium, provided the original author(s) and the source are credited.

\section{REFERENCES}

Acosta JC, O'Loghlen A, Banito A, Guijarro MV, Augert A, Raguz S, Fumagalli M, Da Costa M, Brown C, Popov N, Takatsu Y, Melamed J, d'Adda di Fagagna F, Bernard D, Hernando E, Gil J 
(2008) Chemokine signaling via the CXCR2 receptor reinforces senescence. Cell 133:1006-1018

Alspach E, Flanagan KC, Luo X, Ruhland MK, Huang H, Pazolli E, Donlin MJ, Marsh T, Piwnica-Worms D, Monahan J, Novack DV, McAllister SS, Stewart SA (2014) p38MAPK plays a crucial role in stromal-mediated tumorigenesis. Cancer Discov 4:716-729

Bhaumik D, Scott GK, Schokrpur S, Patil CK, Orjalo AV, Rodier F, Lithgow GJ, Campisi J (2009) MicroRNAs miR-146a/b negatively modulate the senescence-associated inflammatory mediators IL6 and IL-8. Aging (Albany NY) 1:402-411

Blasi F, Carmeliet P (2002) uPAR: a versatile signalling orchestrator. Nat Rev Mol Cell Biol 3:932-943

Borodkina A, Shatrova A, Abushik P, Nikolsky N, Burova E (2014) Interaction between ROS dependent DNA damage, mitochondria and p38 MAPK underlies senescence of human adult stem cells. Aging (Albany NY) 6:481-495

Bourzac K (2014) Biology: three known unknowns. Nature 509:S69S71

Campisi J (2013) Aging, cellular senescence, and cancer. Annu Rev Physiol 75:685-705

Campisi J (2014) Cell biology: the beginning of the end. Nature 505:35-36

Chandler H, Peters G (2013) Stressing the cell cycle in senescence and aging. Curr Opin Cell Biol 6:765-771

Chien Y, Scuoppo C, Wang X, Fang X, Balgley B, Bolden JE, Premsrirut $P$, Luo W, Chicas A, Lee CS, Kogan SC, Lowe SW (2011) Control of the senescence-associated secretory phenotype by NF-KB promotes senescence and enhances chemosensitivity. Genes Dev 25:2125-2136

Collado M, Serrano M (2010) Senescence in tumours: evidence from mice and humans. Nat Rev Cancer 10:51-57

Coppe JP, Patil CK, Rodier F, Sun Y, Munoz DP, Goldstein J, Nelson PS, Desprez PY, Campisi J (2008) Senescence-associated secretory phenotypes reveal cell-nonautonomous functions of oncogenic RAS and the p53 tumor suppressor. PLoS Biol 6:2853-2868

Coppe JP, Desprez PY, Krtolica A, Campisi J (2010) The senescence-associated secretory phenotype: the dark side of tumor suppression. Annu Rev Pathol 5:99-118

Coppé J-P, Rodier F, Patil CK, Freund A, Desprez PY, Campisi J (2011) Tumor suppressor and aging biomarker p16INK4a induces cellular senescence without the associated inflammatory secretory phenotype. J Biol Chem 286:36396-36403

Costantino L, Sotiriou SK, Rantala JK, Magin S, Mladenov E, Helleday T, Haber JE, lliakis G, Kallioniemi OP, Halazonetis TD (2014) Break-induced replication repair of damaged forks induces genomic duplications in human cells. Science 343:88-91

Coussens LM, Zitvogel L, Palucka AK (2013) Neutralizing tumorpromoting chronic inflammation: a magic bullet? Science 339:286-291

d'Adda di Fagagna F (2008) Living on a break: cellular senescence as a DNA-damage response. Nat Rev Cancer 8:512-522

Davalos AR, Coppe JP, Campisi J, Desprez PY (2010) Senescent cells as a source of inflammatory factors for tumor progression. Cancer Metastasis Rev 29:273-283

de Bono JS, Sandhu S, Attard G (2011) Beyond hormone therapy for prostate cancer with PARP inhibitors. Cancer Cell 19:573-574
Freund A, Orjalo AV, Desprez PY, Campisi J (2010) Inflammatory networks during cellular senescence: causes and consequences. Trends Mol Med 16:238-246

Freund A, Patil PK, Campisi J (2011) p38MAPK is a novel DNA damage response-independent regulator of the senescenceassociated secretory phenotype. EMBO J 30:1536-1548

Fumagalli M, d'Adda di Fagagna F (2009) SASPense and DDRama in cancer and ageing. Nat Cell Biol 11:921-923

Garber K (2013) PARP inhibitors bounce back. Nat Rev Drug Discov 12:725-727

Gilbert LA, Hemann MT (2010) DNA damage-mediated induction of a chemoresistant niche. Cell 143:355-366

Gilbert LA, Hemann MT (2011) Chemotherapeutic resistance: surviving stressful situations. Cancer Res 71:5062-5066

Goruppi S, Dotto GP (2013) Mesenchymal stroma: primary determinant and therapeutic target for epithelial cancer. Trends Cell Biol 23:593-602

Gupta SC, Sung B, Prasad S, Webb LJ, Aggarwal BB (2013) Cancer drug discovery by repurposing: teaching new tricks to old dogs. Trends Pharmacol Sci 34:508-517

Hallek M, Chen J, Hemann MT (2014) Sensitizing protective tumor microenvironments to antibody-mediated therapy. Cell 156:590602

Harrison C (2013) Pharmacokinetics: single-cell imaging adds insight into drug action. Nat Rev Drug Discov 12:264

Helleday T, Petermann E, Lundin C, Hodgson B, Sharma RA (2008) DNA repair pathways as targets for cancer therapy. Nat Rev Cancer 8:193-204

Helleday T, Eshtad S, Nik-Zainal S (2014) Mechanisms underlying mutational signatures in human cancers. Nat Rev Genet 15:585598

Jackson SP, Bartek J (2009) The DNA-damage response in human biology and disease. Nature 461:1071-1078

Junttila MR, de Sauvage FJ (2013) Influence of tumour microenvironment heterogeneity on therapeutic response. Nature 501:346-354

Kessenbrock K, Plaks V, Werb Z (2010) Matrix metalloproteinases: regulators of the tumor microenvironment. Cell 141:52-67

Kim JJ, Tannock IF (2005) Repopulation of cancer cells during therapy: an important cause of treatment failure. Nat Rev Cancer 5:516-525

Köpper F, Bierwirth C, Schön M, Kunze M, Elvers I, Kranz D, Saini P, Menon MB, Walter D, Sørensen CS, Gaestel M, Helleday T, Schön MP, Dobbelstein M (2013) Damage-induced DNA replication stalling relies on MAPK-activated protein kinase 2 activity. Proc Natl Acad Sci USA 110:16856-16861

Kuilman T, Peeper DS (2009) Senescence-messaging secretome: SMS-ing cellular stress. Nat Rev Cancer 9:81-94

Kuilman T, Michaloglou C, Vredeveld LC, Douma S, van Doorn R, Desmet CJ, Aarden LA, Mooi WJ, Peeper DS (2008) Oncogeneinduced senescence relayed by an interleukin-dependent inflammatory network. Cell 133:1019-1031

Liu D, Hornsby PJ (2007) Senescent human fibroblasts increase the early growth of xenograft tumors via matrix metalloproteinase secretion. Cancer Res 67:3117-3126

Moiseeva O, Deschênes-Simard X, St-Germain E, Igelmann S, Huot G, Cadar AE, Bourdeau V, Pollak MN, Ferbeyre G (2013) 
Metformin inhibits the senescence-associated secretory phenotype by interfering with IKK/NF-KB activation. Aging Cell 12:489498

Nguyen DX, Bos PD, Massague J (2009) Metastasis: from dissemination to organ-specific colonization. Nat Rev Cancer 9:274-284

Norton L, Simon R (1986) The Norton-Simon hypothesis revisited. Cancer Treat Rep 70:163-169

Ohanna M, Giuliano S, Bonet C, Imbert V, Hofman V, Zangari L, Bille K, Robert C, Bressac-de Paillerets B, Hofman P, Rocchi S, Peyron JF, Lacour JP, Ballotti R, Bertolotto C (2011) Senescent cells develop a PARP-1 and nuclear factor-êB-associated secretome (PNAS). Genes Dev 25:1245-1261

Orjalo A, BhaumikD Gengler B, ScottGK Campisi J (2009) Cell surface $\mathrm{IL}-1 \alpha$ is an upstream regulator of the senescenceassociated IL-6/IL-8 cytokine network. Proc Natl Acad Sci USA 106:17031-17036

Ozdemir BC, Pentcheva-Hoang T, Carstens JL, Zheng X, Wu CC, Simpson TR, Laklai $H$, Sugimoto $H$, Kahlert $C$, Novitskiy SV, De Jesus-Acosta A, Sharma P, Heidari P, Mahmood U, Chin L, Moses HL, Weaver VM, Maitra A, Allison JP, LeBleu VS, Kalluri R (2014) Depletion of carcinoma-associated fibroblasts and fibrosis induces immunosuppression and accelerates pancreas cancer with reduced survival. Cancer Cell 25:719-734

Pallasch CP, Leskov I, Braun CJ, Vorholt D, Drake A, Soto-Feliciano YM, Bent EH, Schwamb J, lliopoulou B, Kutsch N, van Rooijen N, Frenzel LP, Wendtner CM, Heukamp L, Kreuzer KA, Palucka K, Banchereau J (2014) SnapShot: cancer vaccines. Cell 157:516

Palucka K, Banchereau J (2014) SnapShot: cancer vaccines. Cell 157:516-516

Patel KJ, Lee C, Tan Q, Tannock IF (2013) Use of the proton pump inhibitor pantoprazole to modify the distribution and activity of doxorubicin: a potential strategy to improve the therapy of solid tumors. Clin Cancer Res 19:6766-6776

Pulukuri SMK, Knost JA, Estes N, Rao JS (2009) Small interfering RNA-directed knockdown of uracil DNA glycosylase induces apoptosis and sensitizes human prostate cancer cells to genotoxic stress. Mol Cancer Res 7:1285-1293

Rhim AD, Oberstein PE, Thomas DH, Mirek ET, Palermo CF, Sastra SA, Dekleva EN, Saunders T, Becerra CP, Tattersall IW, Westphalen CB, Kitajewski J, Fernandez-Barrena MG, Fernandez-Zapico ME, lacobuzio-Donahue C, Olive KP, Stanger BZ (2014) Stromal elements act to restrain, rather than support, pancreatic ductal adenocarcinoma. Cancer Cell 25:735-747

Rodier F, Coppe JP, Patil CK, Hoeijmakers WA, Munoz DP, Raza SR, Freund A, Campeau E, Davalos AR, Campisi J (2009) Persistent DNA damage signalling triggers senescence-associated inflammatory cytokine secretion. Nat Cell Biol. 11:973-979
Rodier F, Munoz DP, Teachenor R, Chu V, Le O, Bhaumik D, Coppé JP, Campeau E, Beauséjour CM, Kim SH, Davalos AR, Campisi J (2011) DNA-SCARS: distinct nuclear structures that sustain damage-induced senescence growth arrest and inflammatory cytokine secretion. J Cell Sci 124:68-81

Sale JE, Lehmann AR, Woodgate R (2012) Y-family DNA polymerases and their role in tolerance of cellular DNA damage. Nat Rev Mol Cell Biol 13:141-152

Schmitt CA (2003) Senescence, apoptosis and therapy-cutting the lifelines of cancer. Nat Rev Cancer 3:286-295

Sun Y, Nelson PS (2012) Molecular pathways: involving microenvironment damage responses in cancer therapy resistance. Clin Cancer Res 18:4019-4025

Sun Y, Campisi J, Higano C, Beer TM, Porter P, Coleman I, True L, Nelson PS (2012) Treatment-induced damage to the tumor microenvironment promotes prostate cancer therapy resistance through WNT16B. Nat Med 18:1359-1368

Taganov KD, Boldin MP, Chang KJ, Baltimore D (2006) NF-kBdependent induction of microRNA miR-146, an inhibitor targeted to signaling proteins of innate immune responses. PNAS 103:12481-12486

Tell G, Wilson DM III (2010) Targeting DNA repair proteins for cancer treatment. Cell Mol Life Sci 67:3569-3572

Tentori L, Muzi A, Dorio AS, Scarsella M, Leonetti C, Shah GM, Xu W, Camaioni E, Gold B, Pellicciari R, Dantzer F, Zhang J, Graziani G (2010) Pharmacological inhibition of poly(ADPribose) polymerase (PARP) activity in PARP-1 silenced tumour cells increases chemosensitivity to temozolomide and to a N3-adenine selective methylating agent. Curr Cancer Drug Targets 10:368383

Tomé $M$, Sepúlveda JC, Delgado M, Andrades JA, Campisi J, González MA, Bernad A (2014) MiR-335 correlates with senescence/aging in human mesenchymal stem cells and inhibits their therapeutic actions through inhibition of AP-1 activity. Stem Cells 32:2299-2344

Visvader JE, Lindeman GJ (2008) Cancer stem cells in solid tumours: accumulating evidence and unresolved questions. Nat Rev Cancer 8:755-768

Wang Z, Chen W (2013) Emerging roles of SIRT1 in cancer drug resistance. Genes Cancer 4:82-90

Yu M, Tannock IF (2012) Targeting tumor architecture to favor drug penetration: a new weapon to combat chemoresistance in pancreatic cancer? Cancer Cell 21:327-329

Yu M, Ocana A, Tannock IF (2013) Reversal of ATP-binding cassette drug transporter activity to modulate chemoresistance: why has it failed to provide clinical benefit? Cancer Metastasis Rev 32:211227 